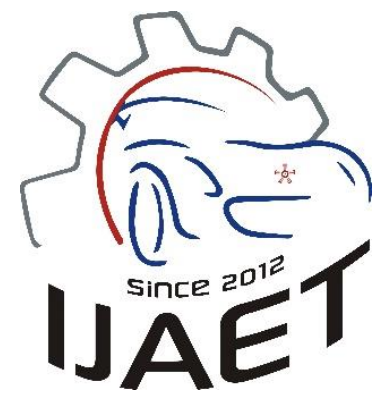

e-ISSN: 2146 - 9067

International Journal of Automotive

Engineering and Technologies

journal homepage: http://ijaet.academicpaper.org

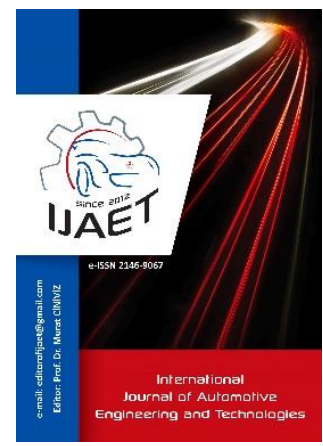

Original Research Article

\title{
Weight Reduction Study on BIW by Using Boron Alloyed Hot Stamping Solution for Front Frame Rail Instead of Conventional HSS or AHSS Applications
}

\author{
Levent Aksel ${ }^{1, *}$, Şaziye Efendıoglu ${ }^{1}$, Harun Yeni ${ }^{1}$, Çiğdem Bilge \\ ${ }^{1}$ TOFAŞ, Turkish Automotive Company R\&D Center, Bursa, Turkey
}

\begin{abstract}
ARTICLE INFO
* Corresponding author

levent.aksel@tofas.com.tr

Received: November 07 2016

Accepted: February 26, 2018

Published by Editorial Board Members of IJAET

(C) This article is distributed by Turk Journal Park System under the CC 4.0 terms and conditions.
\end{abstract}

\begin{abstract}
With the increase of the performance requirements and homologative restrictions, the correct way of choosing the right material on the related area is an inevitable manner for weight reduction of the vehicles. A hot stamped front frame rail which has roughly the same performance with conventional cold stamped one was designed by using tailor welding and patch reinforcement. The part was optimized with full sized frontal crash (EUNCAP), full sized rear crash (TRIAS33) and fatigue simulations. Critical interferences-accelerations into the passenger cabin was considered for acceptance criteria of frontal crash, deformations on fuel system for acceptance criteria of rear crash and plastic deformations on the part, especially suspension fixing points, for acceptance criteria of fatigue test. At the end of all optimizations, the thicknesses of the system were determined as; first tailor welded part: $1.2 \mathrm{~mm}$, second tailor welded part: $2.5 \mathrm{~mm}$ and patch reinforcement: $1 \mathrm{~mm}$. Also some design critics (such as laser cut holes and trims, seal and barrier application for eliminating water infiltration into the bare surfaces of the hot stamped part) were clarified to guarantee the performance of the part during lifecycle of the vehicle. With the final condition, new hot stamped system was weighted $5 \mathrm{~kg}$ and gained a $2 \mathrm{~kg}$ weight reduction.
\end{abstract}

Keywords: Front Frame Rail, Hot Stamping, Boron Alloyed Steel, Body Light Weighting, Frontal Crash, Suspension Fixing

\section{Introduction}

This document represents a weight reduction study and its application on the vehicle body to reduce total weight of the vehicle, energy consumption of the required material and finally $\mathrm{CO}_{2}$ emissions.

There are several types of materials and methods to reduce total body weight. But the multi material concept and the selection of the correct material in correct places is very important for cost effective solutions. [1] Steel has every time the widest usage area on body structure during material selection in multi material concept. Besides, steel grades are increasing thanks to the advances in material engineering. Starting from the mild steel [2] it has evolved today to 2 . and 3 . generation steels. Performance requirements, crashworthiness of the part, formability of the geometry, vehicle target, current homologations etc. must be considered when making the selection of the correct type of steel.

Looking the banana diagram in automotive Body in White (BIW) design in Fig. 1., it can be 
deduced that the designers have a large span of steel material selection during their studies.

In this paper, for having a lightweight body structure, a new front frame rail is designed by using different types of processes like laser tailor welding and patch welding to get a more rigid structure. With these types of processes, it is aimed to eliminate negative effects of the weight-thickness reduction of the component. New front rail design is verified with all aspects of performance requirements of the vehicle like crashworthiness and fatigue life of the vehicle.

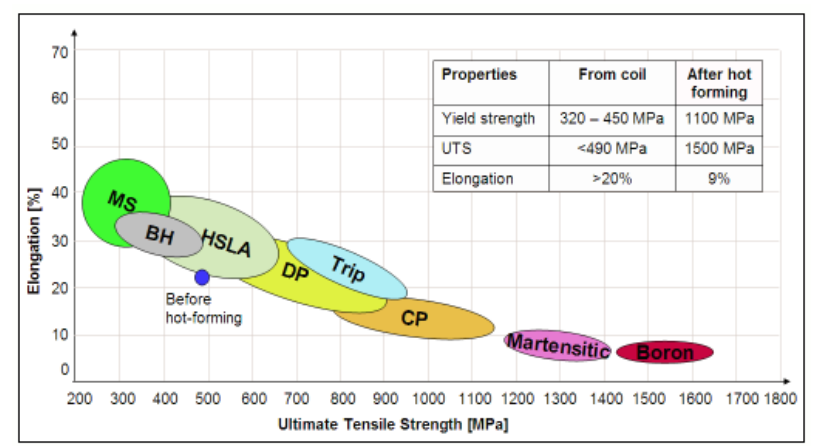

Figure 1. Steel grades in BIW design [3]

\section{Experimental Procedure}

Front frame rail (Fig. 2) is a structural component on the underbody structure and has important performance requirements such as safety cage protection during frontal crash, fuel tank protection during rear crash, fatigue life related to the absorption of the energy which is coming from the road through the front suspension. Thanks to the process advantages of hot stamping process, sheet metal's mechanical properties increase highly and can reach at 1500Mpa without any cracks, wrinkles or spring back, with a good microstructure and a well dispersed hardness [4], [6].

\section{A. Tailor Laser Welding \& Patch Welding}

To reach the high performance targets when optimising the thicknesses, there can be needed to use different processes like tailor welded steel solutions and patch welding. Using these types of processes, the thicknesses of the component can be adjusted with different mechanical properties during the component section [5].

For a lightweight body structure, a new front frame rail is designed by using hot forming material with tailor laser welded two different thicknesses of 1.2 and $2.5 \mathrm{~mm}$. This rail is reinforced by patch welding a $1 \mathrm{~mm}$ FEE 340 material. The section of the rail is optimized considering the crash performances and fatigue life of the vehicle.

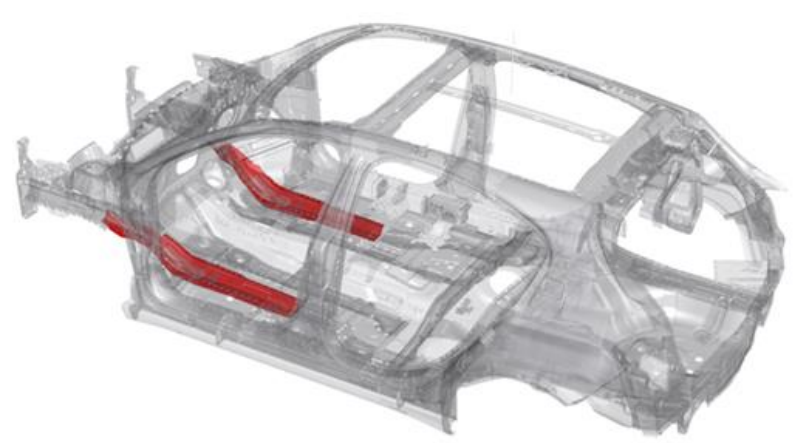

Figure 2. Front frame rail location on BIW

Especially, suspension fixing point is reinforced with patch welding. The distance between the sheet metal parts on the patch welding area is 0 $\mathrm{mm}$ as a process necessity. This situation decreases the inertia on this point. But local rigidity across the fatigue load of the suspension fixing point is rather essential than the inertia. In Fig. 3 is shown a comparison between conventional stamping application with additional reinforced part and new hot stamped patch welded part of the front frame rail.

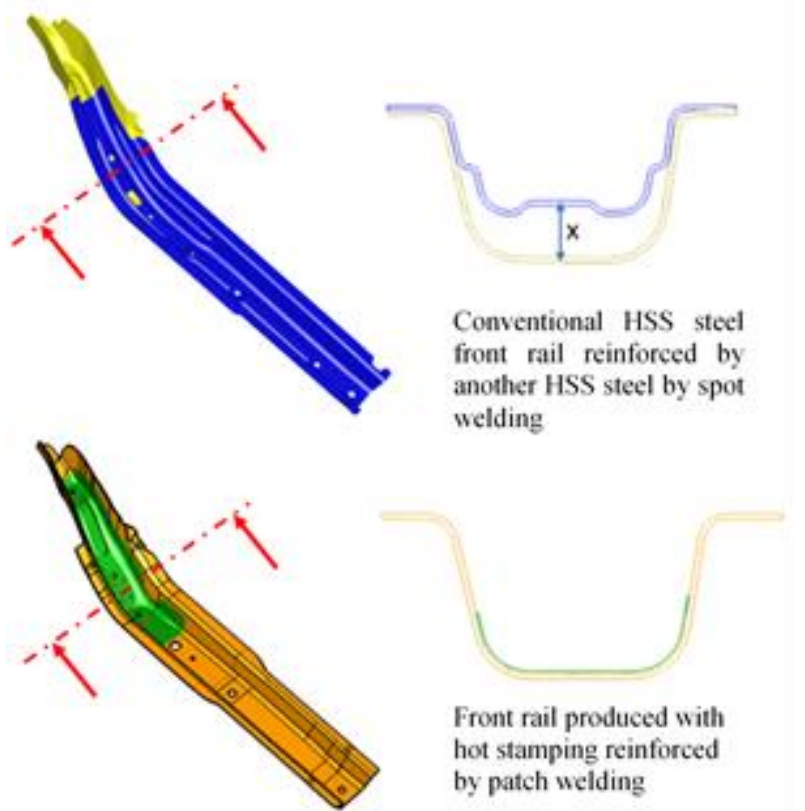

Figure 3. Section comparison of conventional and hot forming applications

$\mathrm{x}$ : the distance is important for the inertia, but when decreasing the distance to $0 \mathrm{~mm}$ the local rigidity of the suspension fixing will increase.

Tailor laser welding of the sheet metals with the thicknesses of $1.2 \mathrm{~mm}$ and $2.5 \mathrm{~mm}$ brings the advantage of optimization of the component for 
crashworthiness. With this process, additional $60 \mathrm{~g}$ weight reduction is gained and also the cycle time of the process is decreased. Basic weight reduction is provided with the elimination of the matching surface which is used for spot welding area. Laser welding is designed for butt welding and there is no need for matching of the surfaces. Fig. 4 shows the comparison of the zones used for spot welding versus laser butt welding.

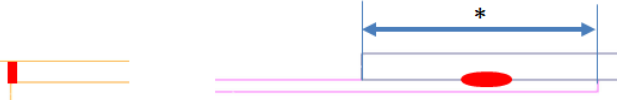

Figure 4. Welding zones: (a) Laser tailor welding, (b) spot welding (* overlap matching area)

\section{B. Cutting and Blanking of the Hot Stamped Part}

One of the most important production problem of the hot stamped parts is cutting. At the end of the process, hot stamped part has a yield strength between $950-1250 \mathrm{MPa}$ and this value makes the cutting operation almost impossible with conventional cutting tools or punch. Even if using cutting operation with blanking tools or punch, the tool life will be very short. In this case, producers have to put up with high repair costs. These additional repairing costs are important, but rather than the cost, repairing time of the tools cannot be accepted for serial production cases. To eliminate this problem, it can be used warm forming process for cutting or blanking operations [7]. Or directly, like in this example, it can be used laser cutting operation both for trim cutting and hole blanking. Laser cutting operation has a cost disadvantage compared to blanking operation. Also with laser cutting operations, trim tolerances are higher than blanking. On trim lines, part has to be at least $\pm 1 \mathrm{~mm}$ tolerance. So the mating parts also ca $\mathrm{n}$ need to be redesigned with the tolerances of hot stamped parts, not to have misaligning holes or mismatching periphery edges.

\section{Forming of the Part}

During the hot stamping process, the heating temperature reaches to $900{ }^{\circ} \mathrm{C}$ and for an ideal martensit structure formation, it has to be cooled approximately at $30{ }^{\circ} \mathrm{C} / \mathrm{s}$ to $250{ }^{\circ} \mathrm{C}$. Thanks to heating effect of the material, part under the press condition can be formed easily. Thus, steel part formability limits enhance drastically. This situation gives designer an opportunity to design the parts with small radii and sharp corners.

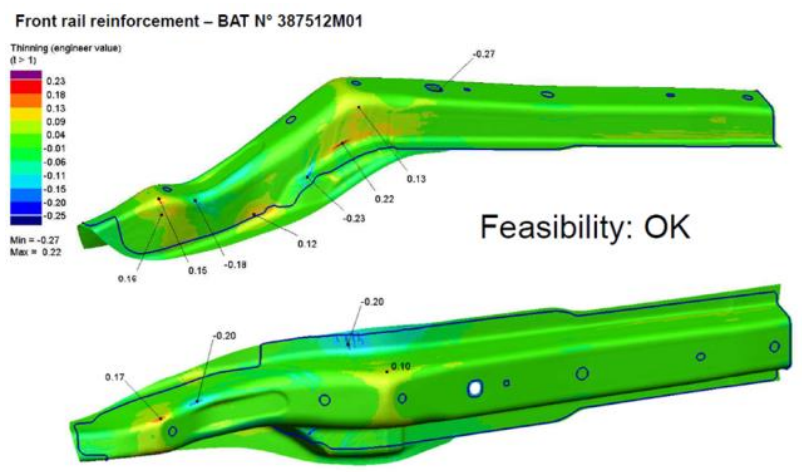

Figure 5. shows final geometry which contains all design parameters indicated above and the thicknesses of the laser tailor + patch welded hot forming parts for front frame rail.

At the end of the process, there is no expectations of problems like spring back or wrinkles in the part geometry. Small radii and completely matching of the patch part on the front rail can be used to get final geometry of the part which guarantee performance requirements. As shown in Fig. 5, hot stamping part can be stamped within the acceptable limits of wrinkle and thinning. The deepest zone of the part has no crack problem or excessive thinning problem. Without any form modification or radii relaxation on the geometry, the same geometry cannot be stamped without cracks or wrinkles with cold stamping die.
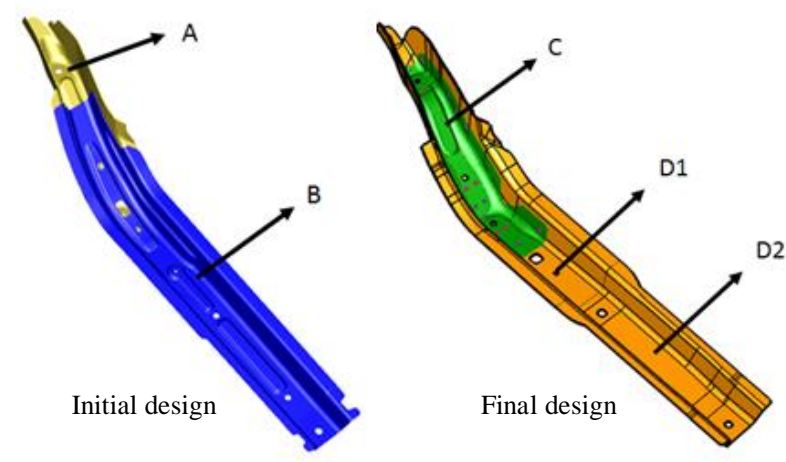

Figure 6. Initial and Final part design material characteristics

Fig. 6 and Table 1. shows initial design and final geometry which contains all design parameters indicated above and the thicknesses of the laser tailor + patch welded hot forming part for front frame rail. 
Table 1. Initial and Final part design material characteristics

\begin{tabular}{|c|c|c|c|c|c|}
\hline Part & Description & Material & $\begin{array}{c}\text { Thickness } \\
\text { (mm) }\end{array}$ & $\begin{array}{c}\text { Yield } \\
\text { Strength } \\
\text { MPa }\end{array}$ & $\begin{array}{c}\text { Tensile } \\
\text { Strength } \\
\text { MPa }\end{array}$ \\
\hline A & Main Rail & $\begin{array}{c}\text { FEE 340 } \\
\text { (HSS) }\end{array}$ & 2,5 & $340-460$ & $\geq 410$ \\
\hline B & $\begin{array}{c}\text { Reinforcement } \\
\text { of Rail }\end{array}$ & FE600DP & 2,2 & $340-440$ & $\geq 590$ \\
\hline C & $\begin{array}{c}\text { Patch } \\
\text { Reinforcement }\end{array}$ & $\begin{array}{c}\text { FEE 340 } \\
\text { (HSS) }\end{array}$ & 1,2 & $340-460$ & $\geq 410$ \\
\hline D1 & $\begin{array}{c}\text { 1. Tailor } \\
\text { welded part }\end{array}$ & $\begin{array}{c}\text { HOT RIV } \\
\text { 1500 }\end{array}$ & 2,5 & $950-1250$ & $1300-$ \\
\hline D2 & $\begin{array}{c}\text { 2. Tailor } \\
\text { welded part }\end{array}$ & $\begin{array}{c}\text { FEE 340 } \\
\text { (HSS) }\end{array}$ & 1,2 & $340-460$ & $\geq 410$ \\
\hline
\end{tabular}

\section{Vehicle Virtual Validations}

Structure and mechanical characteristics of front frame rail is crucial for the safety performance of the vehicle. To protect the safety cage, front rail has to have good energy absorption characteristics and high mechanical properties. Generally, these characteristics are obtained by using functionally graded strength (FGS). FGS structures are designed by optimizing all of the crashworthiness and its deviation by the time of the crash impact (peak forces, max-min acceleration of the deformation, max displacement of the related zone in safety cage etc.) [8]

Front Crash: For the evaluation of the vehicle in Europe Market; within the Euro NCAP (European New Car Assessment Programmed), the vehicle crashes to a static barrier with 64 $\mathrm{km} / \mathrm{h}$ velocity. Fig 7 schematically shows the regulation.

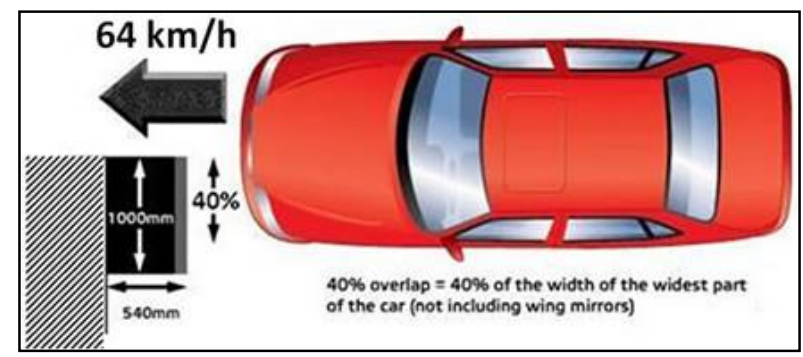

Figure 7. Frontal impact condition of the vehicle for Euro NCAP validation

At the end of the test, the deformations on the vehicle are checked for validation of the vehicle. Basically, there must not be any interferences creating high risk for driver $\&$ passenger safety into the safety cage and the vehicle after crashing must let the passengers going out easily.

In table 2 can be found the interferences into the vehicle categorized according to critical areas for the driver.
New front rail is rigid enough to protect the safety cage and limits the interferences. Buckling of the rail is located on the left side of the vehicle because that it is the barrier impact side. On the right side, the front rail has very few plastic deformations.

Table 2. Interferences into the vehicle during front crash impact

\begin{tabular}{|c|c|c|c|c|c|c|}
\hline & 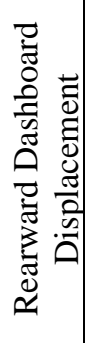 & 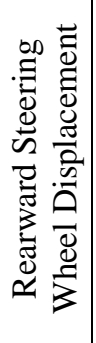 & 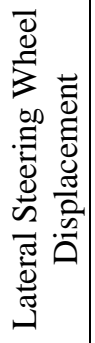 & 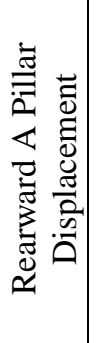 & 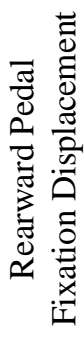 & 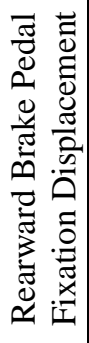 \\
\hline Target & 45 & 45 & 30 & 25 & 90 & 50 \\
\hline Achieved & 16 & 29 & 7 & 20 & 72 & 27 \\
\hline
\end{tabular}

The interference values and other front crash results are positive. In Fig. 8 is shown the crash simulation.

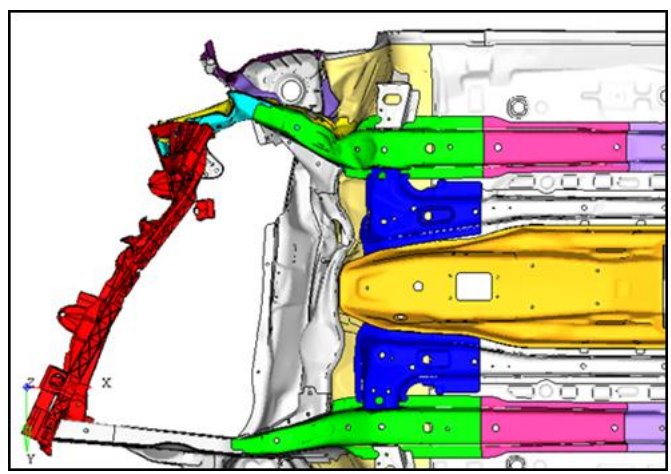

Figure 8. Frontal impact virtual analysis

Rear Crash: For the evaluation of the rear crash performance of the vehicle, TRIAS 33 has been executed. TRIAS 33 basically controls the deformations on the fuel pipes and the fuel tank. Within the TRIAS 33, a rigid barrier has been impacted with $52 \mathrm{~km} / \mathrm{h}$ to the vehicle from the rear side. Fig 9 shows the test condition schematically. 


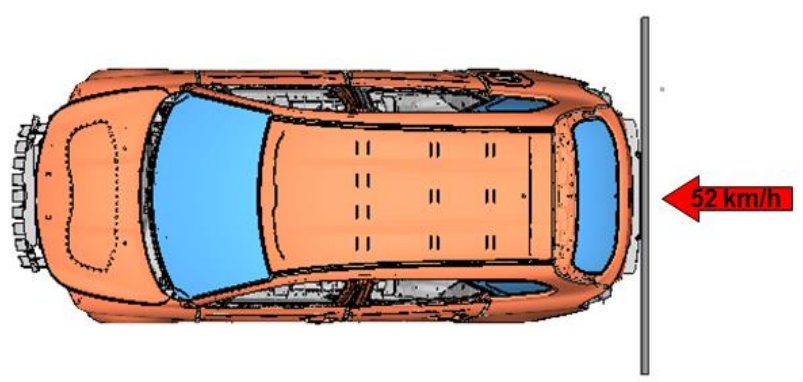

Figure 9. Rear impact condition of the vehicle for TRIAS 33 validation

The vehicle which contains hot stamped front frame rail is crashed by moving rigid barrier and elastic and plastic deformations are checked. The test is resulted as positive. Deformations on the body structure is shown in Fig10 and 11.

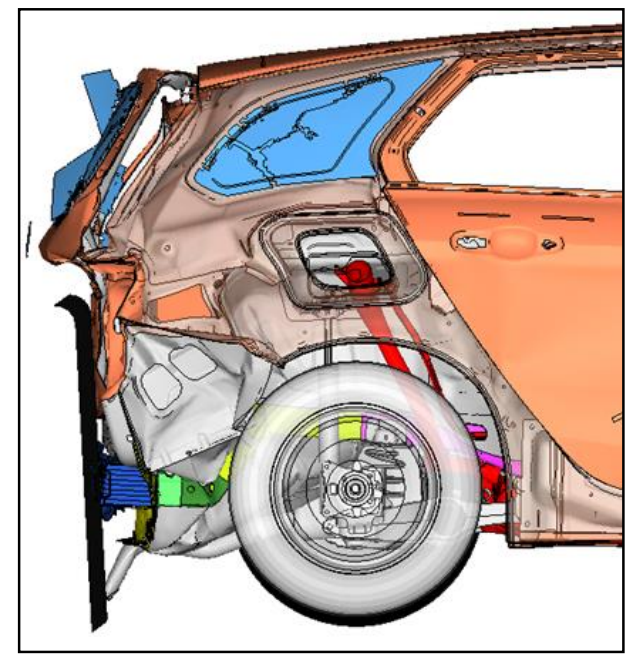

Figure 10. Rear impact virtual analysis result side view

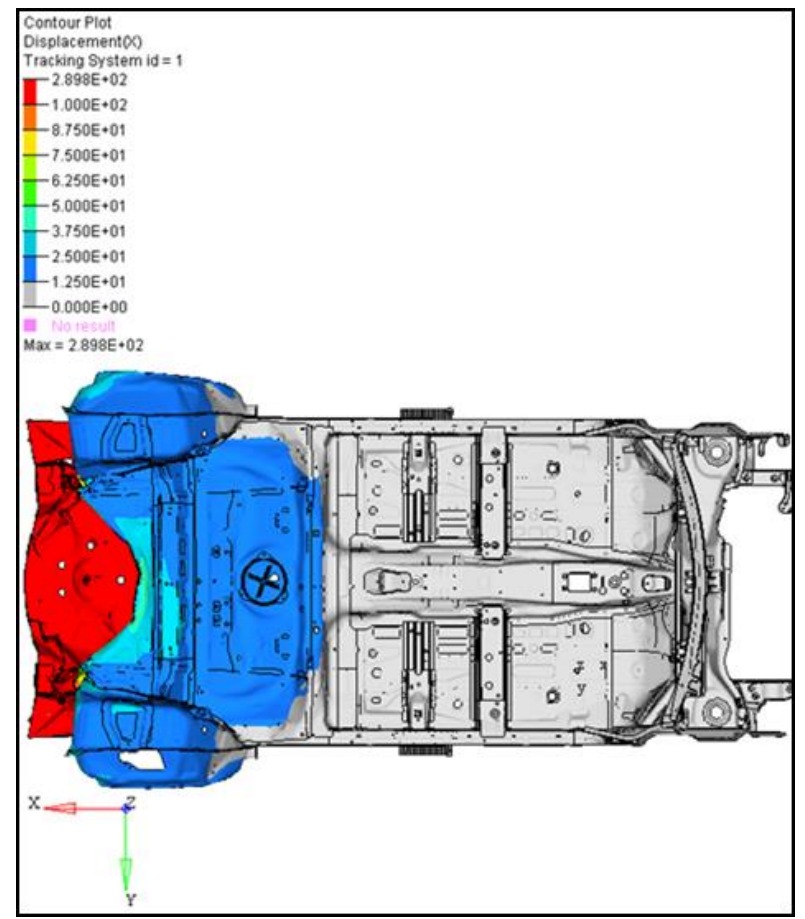

Figure 11. Rear impact virtual analysis result bottom view
Fatigue Performance: Vehicle with the hot stamped front rail part has been verified also with respect to fatigue life of the vehicle. For the fatigue life of the part, the most critical effect comes from the front suspension fixing points. On these points, fixing element selection is very important and they must carry the force coming from road to the vehicle body structure without any structural fail. Fixing nuts are welded on the front rail by projection welding.

With these conditions, vehicle is analyzed. It is investigated if it has a good fatigue life conforming to vehicle targets.

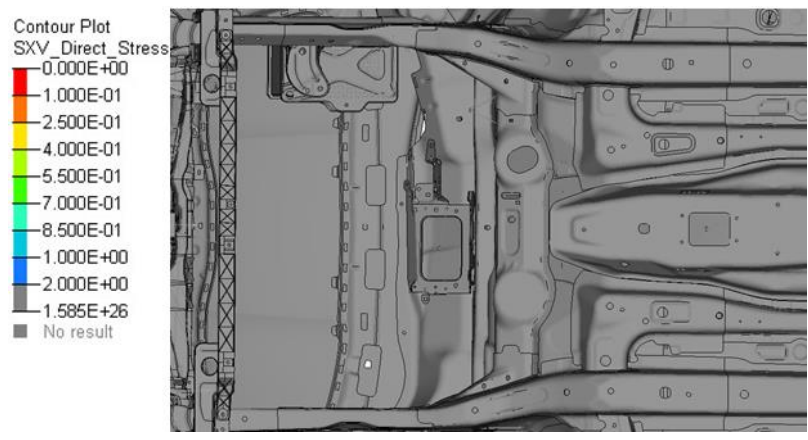

Figure 12. Fatigue life analysis - bottom view

\section{E. Treatment of the Part and Corrosion Behaviour}

Hot stamping part (or blank) is heated to $900{ }^{\circ} \mathrm{C}$ to obtain austenite formation. The blank sheet needs to be transformed quickly to the forming die. If the blank lacks any protective coating, there can be abrasive iron oxide layer on the blank sheet. [9] There are two solutions to eliminate this problem; 1 - heating must be done in a protected zone from atmosphere, 2-an appropriate coating on blank sheet must be applied. Within this study, a blank sheet with hot-dip aluminized coating is selected.

\section{Conclusions}

In the present study, within the BIW, light weighting trials are performed to design a new front frame rail. It is inspected that functional graded strength (FGS) structure formation is inevitable to provide an optimization between thickness decrease and structural performance targets. For creating FGS, alternative types of welding and reinforcing can be used. The virtual analysis shows that the new structure with new front frame rail reinforcement succeeds all safety and structural tests with a $2 \mathrm{~kg}$ decrease in weight per vehicle. 
The producers still have to use additional coating to protect abrasive oxide layer and further studies are necessary to optimize or completely eliminate this requisite.

\section{References}

[1] Novita Sakundarini, Zahari Taha, Salwa Hanim Abdul-Rashid, Raja Ariffin Raja Ghazila, Optimal multi-material selection for lightweight design of automotive body assembly incorporating recyclability, Materials \& Design, Volume 50, September 2013, Pages 846-857

[2] Sun Wenlong, Chen Xiaokai, Wang Lu, Analysis of Energy Saving and Emission Reduction of Vehicles Using Light Weight Materials, Energy Procedia, Volume 88, June 2016, Pages 889-893

[3] Mikael Fermer, Richard Johansson, Peter Nyström \& Olof Hedegard, Local Annealing of Hot-Formed Steel For Improved Ductility and Spot Weld Strength, Materials in Car Body Engineering Conference, May 10-11 2012, Bad Nauheim, Germany

[4] P. Namklang, V. Uthaisangsuk, Description of microstructures and mechanical properties of boron alloy steel in hot stamping process, Journal of Manufacturing Processes, Volume 21, January 2016, Pages 87-100

[5] Marion Merklein, Michael Wieland, Michael Lechner, Stefania Bruschi, Andrea Ghiotti, Hot stamping of boron steel sheets with tailored properties: A review, Journal of Materials Processing Technology, Volume 228, February 2016, Pages 11-24

[6] Junjia Cui, Guangyong Sun, Junrui Xu, Xiaodong Huang, Guangyao Li, A method to evaluate the formability of high-strength steel in hot stamping, Materials \& Design, Volume 77, 15 July 2015, Pages 95-109

[7] Hyunwoo So, Dennis Faßmann, Hartmut Hoffmann, Roland Golle, Mirko Schaper, An investigation of the blanking process of the quenchable boron alloyed steel 22MnB5 before and after hot stamping process, Journal of Materials Processing Technology, Volume 212, Issue 2, February 2012, Pages 437-449

[8] S. Bruschi, A. Ghiotti, Hot Stamping, Reference Module in Materials Science and
Materials Engineering, from Comprehensive Materials Processing, Volume 3, 2014, Pages 27-54, Current as of 28 October 2015.

[9] T. Altan, Hot-stamping boron-alloyed steels for automotive parts, Part II: Microstructure, material strength changes during hot stamping, January18,2007. 